\title{
Опыт составдения аннотированного списка Сводеша для ведийского языка
}

\begin{abstract}
Статья посвящена проблемам, возникающим при составлении 110-словного списка Сводеша для ведийского языка. Качественный список такого рода имеет исключительную важность для лексикостатистической работы с индоиранским и индоевропейским материалом, но составление его осложняется стилистической и хронологической неоднородностью ведийских текстов. В качестве основного идиома был выбран язык Атхарваведы, второй из Вед, по той причине, что в нем меньше лакун и в текстах употребляется больше базисной лексики, в том числе соматической. Была применена семантическая спецификация, используемая в ГлБД (Глобальной лексикостатистической базе данных). При этом текст Атхарваведы сравнивался с Ригведой для получения более надежного результата и исследования языковой эволюции на ранних этапах развития ведийского языка. В результате исследования выяснилось, что (а) 87 элементов списка определяются без проблем; (б) различными для Атхарваведы и Ригведы являются 6 основ; (в) морфологические различия между текстами Ригведы и Атхарваведы засвидетельствованы в 3 случаях; (г) наконец, в 10 случаях было несколько весомых кандидатов на заполнение слота, но работа с текстами позволила сделать уверенный выбор базовых терминов. В тексте Атхарваведы всего 4 лакуны. В пяти случаях в основной слот вынесено две основы по причине супплетивизма, еще в пяти - по причине синонимии. Проведенное исследование показывает, что ведийский список может быть успешно составлен при опоре на тексты и на строгий семантический стандарт.

Ключевые слова: лексикостатистика; список Сводеша; ведийский язык; Атхарваведа; Ригведа; синонимия; супплетивизм.
\end{abstract}

Составление аннотированного 110-словного списка Сводеша для ведийского языка представляется актуальной задачей, поскольку ведийский является одним из древнейших индоевропейских языков и подобный список может представлять повышенный интерес для глоттохронологического и лексикостатистического анализа индоевропейской семьи. Наличие такого рода списков для древних индоевропейских языков представляется особенно важным, потому что их использование для классификации представляется приоритетным, хотя и может быть сопряжено с рядом трудностей филологического характера, с проблемой выбора синонимов в поэтических текстах и т. д. Как показывает опыт таких работ, как Kassian 2011, посвященной составлению 50-словного списка Сводеша для древнегреческого языка Геродота, и Starostin 2019, в которой разбираются и сравниваются относительные скорости замены базисной лексики (по 100-словному списку Сводеша) на протяжении языковой эволюции китайского языка, от раннедревнекитайского к классическому древнекитайскому, среднекитайскому и современному китайскому, задача является в целом успешно осуществимой.

Ведийский язык представляет собой наиболее древнюю разновидность древнеиндийского языка. Его памятники состоят, с одной стороны, из метрической части с текстами, записанными стихотворным размером; она представлена четырьмя Ведами (Ригведа, Атхарваведа, Самаведа и - частично - Яджурведа). С другой стороны, в ведийском корпусе есть прозаическая часть, в которую входят самхиты и брахманы (Wacker- 
nagel 1896: XI-XXXIV). Наиболее древнее состояние отражено в языке Ригведы, причем I-я и X-я мандалы позднее по составлению. Следующий по архаичности текст - Атхарваведа, далее следует Яджурведа и язык прозы. Поскольку для древней Индии при установлении хронологии существует проблема с абсолютными датами, доступны только приблизительные оценки датировки ведийских текстов, основанные в значительной степени на лингвистических данных текстов в сопоставлении с данными других древних индоиранских и, шире, индоевропейских языков и на сопоставлении исторических данных о древней Индии с реальностью, описываемой в ведийских текстах. Считается, что Ригведа была составлена в середине 2-го тысячелетия до н. э. (Elizarenkova 1989: 435-436), а Атхарваведа - несколько позже; так, например, М. Витцель датирует ядро Атхарваведы временем post quem 1200 до н. э. (Witzel 1997: 281). Для ведийского списка как эталон текста мы выбираем Атхарваведу, представленную двумя основными редакциями, Пайппалада (Paippalada) и Шаунака (Śaunaka).

Атхарваведа - второй по древности ведийский текст после Ригведы, датируемый приблизительно рубежом 2-го и 1-го тысячелетий до н. э. Тексты Атхарваведы предпочтительнее, поскольку содержат заклинательные гимны и лучше отражают реальное употребление лексики, в том числе соматической. Практика сбора списка также показала, что в тексте Атхарваведы меньше лакун. Вместе с тем при составлении ведийского списка данные Ригведы невозможно игнорировать, и сравнение наиболее древнего состояния ведийского языка с более поздним, представленным в Атхарваведе, неизбежно становится одной из задач при составлении 110-словного списка Сводеша для ведийского языка.

Основные лексикографические источники, которые были использованы при составлении списка - Большой Петербургский словарь санскрита (BR 1855-1875), словарь языка Ригведы Г. Грассмана (Grassmann 1873) и незаконченный лексикон языка Ригведы (RIVELEX). Для нахождения и подсчета словоформ в текстах Ригведы и Атхарваведы были привлечены конкордансы Lubotsky 1997, Kim 2020, Whitney 1881. Для ведийской литературы, датирующейся временем после РВ и АВ르, использованы конкордансы Bloomfield 1906 и Vishva Bandhu 1935-1965. Для указания форм глаголов в списке использованы работы Bloomfield 2008, Whitney 1885, также для презентных форм - Gotō 1987 и для перфектных форм - Kümmel 2000.

При этом составление списка для ведийского языка наталкивается на ряд проблем, возможность успешного разрешения которых и хотелось бы продемонстрировать в рамках этой работы. В ряде случаев присутствует разветвленная синонимия, и решение о вынесении того или иного слова в список должно приниматься на основании тщательного филологического анализа. В силу ограниченности имеющегося корпуса неизбежны лакуны в списке и немногочисленность контекстов для ряда лексем.

Применяемая семантическая спецификация основывается на работе (Kassian et al. 2010), в которой для каждого слота 110-словного списка Сводеша приводится ряд диагностических контекстов. В статье для сомнительных случаев будут указаны контексты и приведены дополнительные критерии выбора из имеющихся возможных кандидатов на заполнение основного слота списка.

Принципы Глобальной лексикостатистической базы данных (ГАБД) описаны в Starostin 1998-2005; также можно отметить описание в работе Kassian 2011: 65-66.

В работе будут указаны слова, которые бесспорно являются основными как в Атхарваведе, так и в Ригведе (или только в Атхарваведе, что значительно реже), при этом для

\footnotetext{
${ }^{1}$ Она привлекается только в тех случаях, когда соответствующей лексемы или основы нет в собственно четырех Ведах (самхитах).
} 
списка этих случаев будут даны только необходимые краткие комментарии. В основном используется редакция Шаунака (Śaunaka), поскольку существует полное издание текстов (Roth-Whitney 1856-1857; Orlandi 1992), соответственно, примеры из текстов приводятся по этой редакции. Языковые данные Пайппалады используются частично; прежде всего используется 5-я мандала по изданию Lubotsky 2002. Встречаемость исследуемых лексем в корпусе устанавливается по конкордансу Kim 2020.

При описании глаголов указываются основы презенса, аориста и перфекта с опорой на (Gotō 19872; Kümmel 2000³; Whitney 1885), при супплетивизме в основной слот выносятся все дополняющие друг друга основы. Переводы текстов Атхарваведы приведены по изданию Elizarenkova 2005-2010, Ригведы - по Elizarenkova 1989-1999. В отдельных случаях были использованы для сверки значений классический перевод Гельднера (Geldner 1951), современные переводы Джемисон-Бреретон (JamisonBrereton 2014) и Витцеля и др. (Witzel et al. 2007).

Отдельно будут подробно разобраны сомнительные случаи (в которых, например, приходилось делать выбор из ряда синонимов), а также все те случаи, когда для Ригведы основное обозначение в том или ином слоте отличается от устанавливаемого для Атхарваведы. Также особняком будут указаны позиции, в которых тексты Ригведы и Атхарваведы демонстрируют только морфологическую разницу.

Фонетический облик для выносимых в слот основ указывается по стандарту ГАБД (GLD) и по традиционному стандарту записи древнеиндийских текстов (IAST International Alphabet of Sanskrit Transliteration); в комментарии для простоты дана только традиционная запись. Взаимные соответствия транскрипций даются ниже, в таблице 1.

\begin{tabular}{|c|c|c|c|c|c|}
\hline IAST & GLD & IAST & GLD & IAST & GLD \\
\hline$a$ & $\mathrm{a}$ & $\mathrm{k}$ & $\mathrm{k}$ & th & $t^{\text {h }}$ \\
\hline$\overline{\mathrm{a}}$ & a: & $\mathrm{kh}$ & $\mathrm{k}^{\mathrm{h}}$ & $\mathrm{d}$ & $\mathrm{d}$ \\
\hline $\mathrm{i}$ & $\mathrm{i}$ & $\mathrm{g}$ & $\mathrm{g}$ & $\mathrm{dh}$ & $\mathrm{d}^{\mathrm{h}}$ \\
\hline$\overline{1}$ & $\mathrm{i}:$ & gh & $g^{h}$ & $\mathrm{n}$ & $\mathrm{n}$ \\
\hline $\mathrm{u}$ & $\mathrm{u}$ & $\dot{\mathrm{n}}$ & $\mathrm{y}$ & $\mathrm{p}$ & $\mathrm{p}$ \\
\hline$\overline{\mathrm{u}}$ & $\mathrm{u}:$ & $\mathrm{c}$ & č & $\mathrm{ph}$ & $\mathrm{p}^{\mathrm{h}}$ \\
\hline r & $r$ & ch & $\check{c}^{h}$ & $\mathrm{~b}$ & $\mathrm{~b}$ \\
\hline $\bar{r}$ & $\mathrm{r}:$ & $\mathrm{j}$ & 3 & $\mathrm{bh}$ & $\mathrm{b}^{\mathrm{h}}$ \\
\hline 1 & 1 & $\mathrm{jh}$ & $\overline{3}^{h}$ & $\mathrm{~m}$ & $\mathrm{~m}$ \\
\hline 1 & $1:$ & $\tilde{\mathrm{n}}$ & $\mathrm{n}$ & $\mathrm{y}$ & $\mathrm{y}$ \\
\hline e & e: & $t$ & $t$ & $\mathrm{r}$ & $\mathrm{r}$ \\
\hline ai & a:y & thh & $\mathrm{t}^{\mathrm{h}}$ & 1 & 1 \\
\hline $\mathrm{O}$ & O: & $\mathrm{d}$ & $\mathrm{d}$ & $\mathrm{V}$ & $\mathrm{w}$ \\
\hline $\mathrm{au}$ & a:w & dh & $\mathrm{d}^{\mathrm{h}}$ & ś & $\delta$ \\
\hline ṃ & $\tilde{\mathrm{V}}$ & na & $\eta$ & ș & $\mathrm{S}$ \\
\hline ha & $\mathrm{h}$ & $t$ & $t$ & $\mathrm{~h}$ & h \\
\hline
\end{tabular}

Таблиц̧а 1. Соответствия между транскрипциями IAST и GLD

\footnotetext{
${ }^{2}$ Материалы данной работы используются для аннотации глаголов, имеющих презенс I класса или таких, которые не являются презенсами I класса, но считались таковыми по традиции.

${ }^{3}$ С опорой на эту монографию указываются перфектные основы.
} 
Гласные могут иметь слабый носовой призвук, что отмечается в традиционной за-

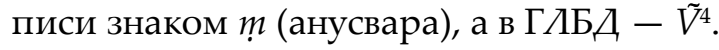

\section{Однозначные случаи}

1. all / весь: w'if-wa- \{viśva-\}

Бесспорно основное слово, имеющее значение 'весь', как для Ригведы, так и для Атхарваведы, четко отличающееся от sárva- 'целый (entire, whole)'. Основа víśva- обладает полисемией 'весь / всякий, каждый', ср. RV X, 60, 6 «Ты наступил на Пани, на всех скупцов, о царь», англ. "You have trodden down the niggards, trodden on all the ungenerous ones, o king», а значение 'всякий, каждый' можно проследить, например, в RV I, 100, 7 «Он один управляет каждым действием», англ. «he alone is lord of every undertaking» (Jamison-Brereton).

2. ashes / пепел, зола: 'a:s-a- $\{a \hat{s} a-\}$

Некоторая проблема состоит в том, что данное слово употреблено только один раз в Атхарваведе (Шаунака) в контексте AVŚ IX, 8, 10 «пусть пеплом станет баласа, мочой болезнетворной!» и два раза в Пайппаладе: AVP XVI, 30, 8; AVP XVI, 74, 10. Несмотря на неясное контекстульное значение, можно утверждать, что слово должно было значить 'зола; пепел'. В пользу этого говорят этимологические связи данного слова: оно производно от корня “ $h_{2} e h_{1} s$ - 'жечь / сушить', как и, например, др.-в.-нем. asca 'зола'; также в ряде дардских и нуристанских языков засвидетельствованы слова с подходящим значением, произведенные от данной основы, ср. кати аsә 'пепел' (EWAia I: 182-183). Более поздние употребления в ведийском также подкрепляют эти доводы, cp. ŚBr. XII, 4, 1, 4. āsāh pāmsavaḥ 'пеплы (золы)-пески’.

3. bark / кора: в Ведах (самхитах) не засвидетельствовано. В более поздних памятниках ср. tvác- с полисемией ‘кожа / шкура / кора’ (BR 1861: 463-464). Также стоит отметить термин bāhya- 'внешняя кора дерева', употребленный в таком значении в ŚBr. III, 7, 1, 8; первое значение - собственно 'внешний' (BR-5 1868: 84).

5. big / большой: mah-'ant- \{mahánt- $\}$

Также более архаичные варианты máh- и mahí- < *meǵ $h_{2}$-. Сочетается с максимальным количеством объектов.

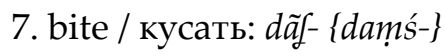

Традиционно относится к I классу, но содержит нулевую ступень и относится к так называемым аористным презенсам (Aorist-Präsentien) (Gotō 1987: 74; Hill 2007: 172-173). Финитные формы этого глагола плохо представлены в Ведах (самхитах), но причастные употребления безусловно доказывают, что это основное обозначение. Так, в Ригведе засвидетельствованы презентное причастие dáśant- (RV I, 189, 5) и причастие интенсива dándaśāna- (RV X, 95, 9); и в Ригведе, и в Атхарваведе представлены перфектное активное причастие dadaśváms- (AVP III, 16, 6; RV IV, 38, 6) и пассивное перфектное причастие dașțá- (AVP III, 16, 6; AVP XX, 14, 9). Кроме того, в более поздних ведийских и послеведийских текстах встречаются финитные формы этого глагола, например, 3 л. мн. ч. dáśanti

\footnotetext{
${ }^{4}$ В данном случае сознательно игнорируется фонетическая разница между анусварой и анунасикой (последняя означает назализацию предшествующей гласной) в связи с тем, что анунасика в рассматриваемых формах не встречается.
} 
(ŚBr. VII, 4, 1, 29). Всего в Атхарваведе Пайппаладе 9 употреблений форм этого глагола, а в Шаунаке - 2 (Kim 2020: 329), в Ригведе - 4 употребления (Lubotsky 1997: 655).

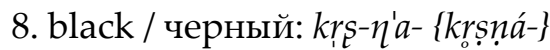

9. blood / кровь: 'as-ri-ž- $\{a ́ s r j-\}$

10. bone / кость: 'ast ${ }^{h}-i$ - $\{a ́ s t h i-\}$

12. burn tr. / жечь перех.: daf- $\{$ dah- $\}$

Презенс (I) 3 ед. dáhati, корневой атематический аорист 3 ед. adhāk (Gotō 1987: 174176) Корень $k s ̦ \bar{a}-$, родственный на праязыковом уровне dah- ${ }^{5}$, встречается только один раз в Ригведе (редуплицированный аористный инъюнктив), 4 раза в Пайппаладе и 2 в Шаунаке в сходных контекстах (Kim 2020: 235).

13. nail / ноготь: $n a k^{h}-{ }^{\prime} a-\{$ nakhá- $\}$

14. cloud / облако: n'ab ${ }^{h}$-as- \{nábhas-\}

15. cold / холодный: \{i- -t'a- \{śittá-\}

16. come / приходить: gam- \{gam-\}

Презенс (с суффиксом -cha) gáchati, корневой тематический аорист 1 ед. ágamam, 3 ед. ágan, перфект 3 ед. jagámma, 3 мн. ч. jagmús (Gotō 1987: 73; Whitney 1885: 34; Kümmel 2000: 155-160). Относится традиционной индийской грамматикой к I классу (Whitney 1885: 34), но такая классификация смешивает собственно презенсы с полной или продленной ступенью корня с другими образованиями (Gotō 1987: 73).

17. die / умирать: mar- $\{$ mar- $\}$

Презенс (IV) 3 ед. mriyáte (с вторичным ударением как у пассива, возможно, вызванным неудобством прямого отражения последовательности *CóriV-, см. работу Kulikov 1997); корневой атематический аорист 3 ед. amrta; перфект 3 ед. ч. mamára, 3 мн. ч. mamrús (Gotō 1987: 82; Kümmel 2000: 370-372). Зафиксирована форма márati, которая в литературе считалась I классом презенса (Whitney 1885: 124), однако П. Тедеско показал, что основа mára-, встречающаяся в Ригведе, функционально соответствует футуральной основе marișya-, соответственно, представляет собой субъюнктив корневого аориста, употребляемый в значении будущего времени (Tedesco 1944: 212-213).

18. dog / собака: fwan- \{śván-\}

19. drink / пить: $p a:-\{p \bar{a}-\}$

Презенс 3 ед. píbati I $\leftarrow$ III / III (в нотации Kulikov 2008, 2017) с тематизацией изначально атематического редуплицированного презенса (Gotō 1987: 72), (II) 3 мн. pānti (RV II, 11, 14); аорист 3 ед. apāt, перфект 3 ед. papaú, 3 мн. papús (Whitney 1885: 95-96; Kümmel 2000: 308-309).

20. dry / сухой: \{us-ka- \{śúșka-\}

21. ear / yxo: k'arn-a- \{kárṇa-\}

23. eat / есть: $a d-\{a d-\}$ u af- $\{a s ́-\}$

Невозможно уверенно сделать выбор между этими двумя корнями с презентными основами: (II) 3 ед. átti, 3 мн. adánti и (IX) 3 ед. aśnáti, 3 мн. aśnánti соответственно.

\footnotetext{
${ }^{5}$ Корень dah- отражает праформу ${ }^{*} d^{h} e g^{w h}$-, в то время как $k s ̣ \bar{a}-$ выводится из ${ }^{*} d^{h} g^{w h}-e h_{1}\left(\operatorname{LIV}^{2}: 133-134\right.$; EWAia I: 712-713).
} 
Авторы словаря Rigveda-Lexikon, следуя традиционному взгляду, считают, что здесь налицо следующий супплетивизм: корень ghas- 'поглощать' служит аористом, а деноминативная основа āvaya- образует имперфект (RIVELEX 1: 117). Тем не менее, формы этих глаголов редки в Атхарваведе и встречаются в основном в местах, имеющих параллели в Ригведе (Whitney 1881: 51, 103). Поэтому я предпочитаю не включать их как отдельные корни.

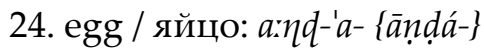

25. еуе / глаз: $a k s-\{a k s ̣-\}$

Две основы, ákși- и akșán-.

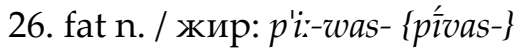

27. feather / перо: par- $\eta^{\prime} a-\{$ parná-\}

28. fire / огонь: agn-'i- \{agní-\}

29. fish / рыба: m'atsy-a- \{mátsya-\}

30. fly / летать: pat- \{pat-\}

Презенс (I) 3 ед. pátati, 3 мн. pátanti, аорист 3 ед. ápaptat, перфект 3 ед. papāta; также áya-основа patáyati. Как показал $\lambda$. Куликов, образования pátati и patáyati противопоставлены как предельный и непредельный глаголы, соответственно, они параллельны русской паре 'лететь' - 'летать' (Kulikov 2008). В применяемой спецификации при наличии противопоставления значений 'летать' и 'лететь' предлагается брать соответствующие слова как синонимы (Kassian et al. 2010: 60).

31. foot / нога: pad- \{pád-\}

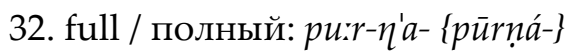

33. give / давать: $d a:-\{d \bar{a}-\}$

Презенс (III) 3 ед. dádāti, аорист 3 ед. ádāt, перфект 3 ед. dadaú (Whitney 1885: 71-72).

34. good / хороший: w'as-u- \{vásu-\}

Синоним bhadrá- имеет первое значение 'благой, счастливый' и часто упоминается по отношению к божествам (Lubotsky 1997: 975-976; Kim 2020: 491-492).

35. green / зеленый: f'ar-i-ta- \{hárita-\}

36. hair / волосы: k'e:-a- $\{k e ́ s ́ a-\}$

37. hand / рука: fías-ta- \{hásta-\}

39. hear / слышать: \{raw- \{́srav-\}

Презенс (V) 3 ед. śrnóti, śrnuté, корневой атематический аорист 1 ед. áśravam, перфект 3 ед. śuśrāva (Whitney 1885: 179-180). Форма 2 ед. śrosi представляет собой изолированный -si-императив к сигматическому аористу (Cardona 1965; Bammesberger 1982/3; Shields 1997).

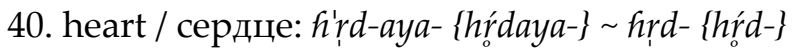

41. horn / рог: אring-a- \{śrínga-\}

42. I / я: afiam-\{ahám-\} ma $\{m a\}$

Основа косвенных падежей ma- $\{m a-\}$. 
43. kill / убивать: fan- $\{$ han- $\}$

От этого корня регулярно образуются только презентные и перфектные формы: презенс (II) 3 ед. ч. hánti, 3 мн. ч. ghnánti, имперфект 3 ед. ч. áhan, перфект 3 ед. ч. jaghấna (Whitney 1885: 202-203; Kümmel 2000: 603-606).

wad ${ }^{h}-\{v a d h-\}$

От данного корня образуется сигматический аорист ávadhīt.

44. knee / колено: క̌'a:n-u- \{jấnu-\}

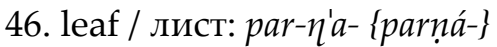

47. lie / лежать: $\{a y-\{$ śay-\}

Презенс (II) 3 ед. śéte, статив śáye (Whitney 1885: 174; Kümmel 1996: 10).

48. liver / печень: y'ak-ri-t- \{yákrt-\}

49. long / длинный: $\operatorname{dirg}^{h}-{ }^{\prime} a-\{$ dīrghá-\}

50. louse / вошь: не засвидетельствовано. В более поздних древнеиндийских текстах уйkayúk $\bar{u}-$ (BR-6 1871: 177-178).

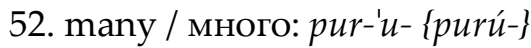

Отличается от менее употребительной основы bhúri- 'многий, многочисленный; много; частый; часто', которая чаще встречается адъективно (Kim 2020: 507; Lubotsky 1997: 997; Grassmann 1873: 952-953).

53. meat / мясо: mãas-'a- \{māmssá-\}

55. mountain / ropa: gir-'i- \{girí-\}

56. mouth / рот: a:s- $\{\bar{a} s-\}$

От этого корня три основы: ás- (только RV абл. ед. ч. и твор. ед.), āsíya- (BR-1 1855: 744;

Grassmann 1873: 191) и а̄sán- / āsn- (BR-1 1855: 736; Grassmann 1873: 190).

57. name / имя: n'a:m-an- \{nấman-\}

58. neck / шея: gri:-w'a:- \{grīoáa-\}

59. new / новый: n'aw-a- \{náva-\}

61. nose / Hoc: nas- \{nás-\}

Корневое имя па́s- представлено как в Атхарваведе (обе редакции), так и в Ригведе (Lubotsky 1997: 803).

Существует традиция выделять также основу nás̄ā- (или ná́sa-), используемую в дуалисе (BR-4 1865: 126-127; Grassmann 1873: 720, 726; Kim), однако разумнее вслед за А. Аубоцким объединять эти формы под одной основой. Также производное ná́sikā- (BR-4 1865: 128; Grassmann 1873: 726).

62. not / не: $n a-\{n a ́-\}$

Отличается от прохибитивной частицы $m \bar{a}-$.

63. оne / один: 'e-ka- \{éka-\}

66. red / красный: l'o:h-i-ta-\{lóhita-\} r'o:f-i-ta-\{róhita-\}

Ж. p. lóhinī- róhinī-

Также в ведийском, начиная с Атхарваведы, засвидетельствована основа rudhirá, которая родственна lóhita- róhita- и является прямым соответствием греч. દ̇@vӨ@ós < и.-е. * $h_{1} r u d^{h}-r o-$ 
'красный'. Она переводится как 'красный, кровавый', а в позднейшем языке начинает использоваться для обозначения ‘крови’ (BR-6 1871: 386-387; EWAia II: 453). Она употребляется 5 раз в Пайппаладе (из них 3 раза в одном гимне) и 1 раз в Шаунаке (Kim 2020: 597).

67. road / дорога: $p a t^{h}-\{$ path-\}

Основы: pánthā- / pathí- / path-. Им. ед. ч. pánthās, лок. ед. ч. pathí, дат.-твор. мн. ч. pathíbhis.

68. root / корень: $m^{\prime} u: l-a-\{m \dot{u} l a-\}$

69. round / круглый: не засвидетельствовано.

70. sand / песок: pãas-'u- \{pāmsú-\} и s'ik-a-ta:- \{síkatāa-\}

Данные слова употребляются как синонимы, которые сложно различить из-за малочисленности контекстов: pāṃsú- употребляется по 2 раза в Пайппаладе и Шаунаке (Kim 2020: 431), a síkatā- по 3 раза соответственно (Kim 2020: 758). В контексте AVŚ VII, 109, 2 они употребляются в одном стихе, но на его основании нельзя провести четкое разгра-

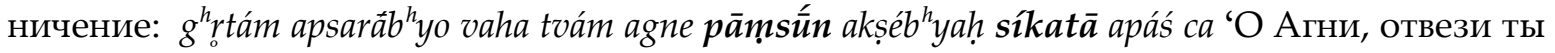
жир для (нимф) апсарас, Пыль для игральных костей, песок и воду!"

71. say / сказать: braw- $\{$ brav- $\}$

Презенс (II) 3 ед. brávīti, 3 мн. bruvánti, имперфект 3 ед. ábravìt (Whitney 1885: 107).

wač- $\{$ vac- $\}$

Редуплицированный тематический аорист 3 ед. avocat с гласной удвоения -a-. Также от данного глагола употребляется редуплицированный презенс (III) vivakti и перфект 3 ед. vavāca и иvá́ca, 3 мн. ucús (Kümmel 2000: 441-444).

Отличается от vad- 'говорить; сказать; повествовать; восхвалять' (BR-6 1871: 649-657; Grassmann 1873: 1199-1201), встречающегося в основном в первом и третьем значениях и часто обозначающего приподнятую, торжественную речь.

72. seе / видеть: paf- \{paś-\} spaf- \{spaś-\}

Презенс (IV) 3 ед. páśyati.

darf- $\{$ darś- $\}$

Перфект dadárśa, сигматический аорист adrkș- (Whitney 1885: 78; Grassmann 1873: 62; Kümmel 2000: 231-233).

73. seed / семя: b'i:̌̌̆-a- $\left\{b_{\hat{\imath}} j a-\right\}$

74. sit / сидеть: a:s- $\{\bar{a} s-\}$

Презенс (II) áste. Корень sad- имеет значение 'сесть, садиться', соотносится с ās- как инхоативный. На английский последовательно переводится как 'sit down’.

75. skin / кожа: twač- $\{$ tvác- $\}$

78. smoke / дым: $d^{h} u:-m^{\prime} a-\{d h \bar{u} m a ́-\}$

79. stand / стоять: $s t^{h} a:-\{$ sth $\bar{a}-\}$

Презенс 3 ед. tíșthati IŁIII / III (в нотации Kulikov 2008, 2017) с тематизацией изначально атематического редуплицированного презенса (Gotō 1987: 72), корневой атематический аорист 3 ед. ásthāt, перфект 3 ед. tașțāú (Whitney 1885: 194-195; Kümmel 2000: 580-582).

81. stone / камень: 'af-man- \{áśman-\}

82. sun / солнце: s'u:r-ya- \{súrya-\} 
83. swim / плавать: plaw- \{plav-\}

Презенс (I) 3 ед. pl'aw-a-te (Gotō 1987: 214-215).

85. that / тот: sa- $\{$ sá- $\} /$ ta- $\{$ tá- $\}$

Данное супплетивное местоимение является самым употребительным дейктическим местоимением в ведийских текстах и имеет значение 'тот; он, она, оно' (Gotō 2013: 67-69). Обычно «отсылает к чему-то уже известному как к только что упомянутому или к общеизвестному» (Macdonell 1916: 293). Для более конкретного дистального дейксиса служит местоимение asáu-.

as-'a:w \{asáu-\}

Имеет значение 'вот тот'. У этого местоимения три формы: asáu-, adás и amú-; две последние используются в косвенных падежах (Gotō 2013: 71-73). По мнению исследователей, все эти основы так или иначе восходят к праязыковому дейктическому местоимению *u 'там’ в полной ступени *ew- (возможно, новой) с различными наращениями, подробный сценарий и литература могут быть найдены в работах (Wackernagel 1930: 530; EWAia I: 98; Gotō 2013: 71-73; LIPP 2: 191, 821).

86. this / этот: $a-\{a-\} \sim i-\{i-\}, a y-\{a y-\}$

Местоимение значит 'вот этот’ (в непосредственной близости к говорящему) и противопоставлено asáu- (Gotō 2013: 70-71).

87. thou (you) / ты: tuw-'am \{tuvám\} tw-am \{tvám\}

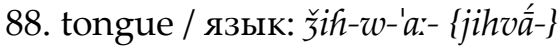

91. two / два: dwa- $\{d v a ́-\} \sim d u w ' a-\{d u v a ́-\}$

92. walk (go) / идти: $i-\{i-\}$

Презенс éti, 3 мн. yánti, перфект 3 ед. iyāya (Kümmel 2000: 98-100).

$g a:-\{g \bar{a}-\}$

От этого корня образуется корневой атематический аорист $3 \mathrm{sg}$. agāt и более редкий редуплицированный презенс (III) jígāti (Whitney 1885: 35).

93. warm (hot) / теплый (горячий): us-ๆ'a- \{ușṇá-\}

Данное слово обладает полисемией 'теплый / горячий'.

95. we / мы: way-'am \{vayám\}

Косвенная основа as-m'a- \{asmá-\}.

96. what / что: ka-d \{kád\}

97. white / белый: fwe:t-'a- \{́svetá-\}

В Атхарваведе есть также основа śvitrá- 'белый / светлый', производная от того же корня (BR-7 1875: 422; Grassmann 1873: 1435; Kim 2020: 698), но она не выступает в качестве базового слова ‘белый’.

98. who / кто: $k a-\{k a ́-\}$

100. yellow / желтый: fíar-i-ta- \{hárita-\}

101. far / далеко: du:r-'e: \{dūré\} и a:r-'e: \{āré\}

Невозможно уверенно сделать выбор между этими двумя словами. Второе слово встречается только в Ригведе и Атхарваведе и в постведийский период практически не представлено (BR-1 1855: 686, 689). 
102. heavy / тяжелый: gur-'u- \{gurú-\}

103. near / близко: 'an-ti- \{ánti-\}

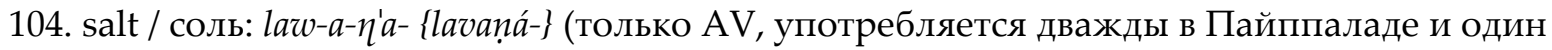
раз в Шаунаке (Kim 2020: 605)).

105. short / короткий: не засвидетельствовано. В Ведах есть основа krdhú- 'укороченный / недостаточный', она один раз употреблена уже в Ригведе (Lubotsky 1997: 447) и один раз в Атхарваведе (Kim 2020: 227); позднее появляется слово hrasvá- 'коротий; небольшой', оно употребляется, например, в контекстах ŚBr. I, 4, 4, 7; III, 7, 2, 7; TS II, 6, 11, 5; VI, 6, 4, 2.

106. snake / змея: 'ah-i- \{áhi-\}

107. thin / тонкий: $\tan ^{-} \mathbf{u}$ - $\left\{\operatorname{tanú}^{-}\right\}$

Данная основа засвидетельствована впервые только в брахманах (EWAia I: 620), но других кандидатов в принципе нет, а его безупречная индоевропейская этимология < *ñH-u- (EWAia I: 620-621) указывает на древность образования.

108. wind / ветер: w'ar-ta- \{váta- $\}$

109. worm / червь: $k^{\prime} r-m-i-\{k r ́ m i-\}$ (надежно только AV)

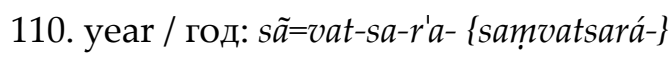

Таким образом, по тексту Атхарваведы для 110-словного списка Сводеша представляется возможным установить 87 основ, что можно считать солидным показателем. При этом во всем списке есть только четыре лакуны: 3. bark / кора; 50. louse / вошь; 69. round / круглый; 105. short / короткий. Они, очевидно, объясняются ограниченностью корпуса ведийских текстов. Наконец, только для одного слота, 107. thin / тонкий, была взята основа, встречающаяся в более поздних ведийских текстах, но такой выбор оправдан отсутствием любых других кандидатов.

На следующем этапе целесообразно рассмотреть три типа случаев:

1) разные лексемы в Ригведе и Атхарваведе;

2) морфологические расхождения между Ригведой и Атхарваведой;

3) случаи, когда было сложно сделать выбор между синонимами.

1) Расхождения между Ригведой и Атхарваведой

6. bird / птица: RV wi- \{ví-\} / we:- \{vé-\}, way-\{váy-\} - AV paks-'in-\{pakșin-\}

В Ригведе основным обозначением служит основа ví- / vé-, váy- 'птица'. Она имеет надежную индоевропейскую этимологию, родственна др.-арм. haw 'птица; петух; кури-

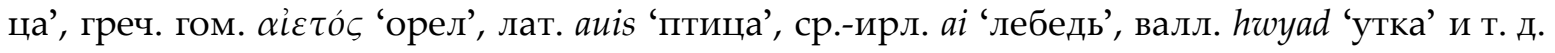
и восходит к праформе *h2wei- (EWAia II: 507-58).

ví- / vé-, váy- встречается также и в Атхарваведе, но как архаизм: все контексты за исключением одного параллельны контекстам Ригведы (Kim 2020: 615; Whitney 1881: 268). Независимое от Ригведы употребление содержится в следующем месте: AVŚ VI, 2, 2 á yám viśántíndavo váyo ná vorkșám ánd ${ }^{h} a s a h$ «(он тот), в кого входят капли Сомы, как птицы (устраиваются) на дереве».

Для Атхарваведы же основным определенно является слово pakșín- с полисемией 'пернатый / птица'. Внутренняя форма данного слова прозрачна - это субстантивация прилагательного с продуктивным суффиксом -in, образованное от pakșá- 'крыло / плечо, 
бок (человека)' (BR-4 1865: 344-346; Grassmann 1873: 757), не имеющего надежной этимологии за пределами индоиранской группы языков (EWAia II: 62).

В индоарийских языках послеведийского периода преобладают рефлексы именно этой основы, ср. (Turner 1962-1985: 7636) с большим количеством примеров.

В данном случае речь идет о замене слова с надежной индоевропейской этимологией на эпитет. Подобный же процесс происходил в иранских языках: рефлексы родственной праиранской основы *wi- / *way- 'птица' отражаются в авест. vi-, vay- 'птица' и в среднеперсидском way 'птица' (MacKenzie 1986: 89), но в большинстве среднеиранских и современных иранских языков данная основа вытеснена другими, в том числе *mrga- (ESIJ 5: 379-383).

11. breast (грудь) RV w'aks-as- \{vákșas\} - AV 'ur-as- \{úras-\}

В Ригведе основным словом для обозначения 'груди', как мужской, так и женской (но не в смысле 'грудь, которой кормят детей', ср. stána- 'женская грудь'), следует признать vákșas-. Оно встречается в тексте 9 раз (Lubotsky 1997: 1215), в то время как úrasтолько два раза, причем в поздних мандалах (RV I, 158, 5; RV X, 155, 4). Можно привести следующие примеры, доказывающие обоснованность именно такого выбора: RV I, 64, 4 «на груди они (Маруты) носят золотые пластинки для блеска»; RV I, 92, 4 «она обнажает грудь, словно корова - вымя».

Основа úras- же явно становится основным обозначением груди в Атхарваведе, как мужской, так и женской (Kim 2020: 180). При этом основа vákșas- засвидетельствована уже только в связанном виде в составе двух композитов: rukmávakșas- 'золотогрудый, несущий на груди золотые украшения (эпитет Марутов)' и синонимичного híranyavakșas'золотогрудый' (Kim 2020: 596, 808; Whitney 1881: 255; MW 1899: 882, 1300). Ср. пример из Атхарваведы для слова úras-: AVŚ X, 3, 11 «этот варана на груди у меня, царь».

Происхождение слова vákșas- не получило однозначного убедительного объяснения. М. Майрхофер полагает, что сравнения с осетинским иронск. wæxsk (уæxск) / диг. usqæ, wæskæ (ускæ, уæскæ) 'плечо’ (ср. Abaev 4: 100-101) или с др.-инд. vakșánฺ̄- 'утроба' неубедительны; при этом исследователь не исключает возможности происхождения от глагольного корня vakṣ- 'расти' < и.-ир. *(H)uakš- 'расти' (EWAia II: 487-488).

При этом úras- является прозрачным производным от прилагательного иrú- 'широкий’ (EWAia I: 226). Таким образом, несмотря на то, что оно имеет более надежную этимологию, чем vákșas-, встречающееся в Ригведе, в данном случае опять можно было бы думать о вытеснении основного обозначения эпитетом.

Однако если учитывать характер более поздних данных, приходится признать, что это достаточно спорный случай. Достаточно заметить, что обе основы употреблялись в послеведийскую эпоху в древнеиндийском, а их производные имеют продолжение в среднеиндийских и новоиндийских языках.

Рефлексы vákșas-, засвидетельствованные в индоарийских языках, в большинстве своем начинают обозначать ‘бок', а также 'легкое' и 'вымя’, хотя пракритские основы vakkha-, vaccha- еще имеют значение ‘грудь’ (Turner 1962-1985: 11188).

Соответствия úras- и прилагательного urasá- 'с сильной грудью' также нашли продолжение в индоарийских языках (Turner 1962-1985: 2350).

Соответственно, в данном случае нельзя исключать и диалектных или стилистических различий между текстом Ригведы и Атхарваведы.

54. moon / луна: RV ma:s- \{mấs-\} - AV čand-r'a- \{candrá-\}

В Ригведе сохраняется древнее имя та́́s- ‘луна / месяц' (BR-5 1868: 758; Grassmann 1873: 1036). Оно имеет безупречную индоевропейскую этимологию: тох. А mañ, тох. В теп̃e

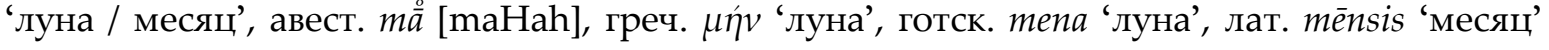
и т. д. $<{ }^{*}$ meh $_{1} n_{\circ} s^{-}$(EWAia II: 352-353). 
Основным обозначением луны уже в Атхарваведе становится основа candrá- (фонетический вариант ścandrá-). Данное слово образовано от корня (ś)cand- < *(s)kend- 'блестеть’ (EWAia I: 528-529; LIV2: 554) и представляет собой очевидный эпитет, так что в данном случае опять речь идет о замене старого обозначения эпитетом, при этом másв Атхарваведе удерживает свое второе значение 'месяц', как и, например, лат. mēnsis.

Дюбопытно, что засвидетельствован также поэтический композит candrámās-, имеющий значение 'луна, бог луны' (буквально ‘блестящая луна') (BR-2 1858: 943; Grassmann 1873: 436). Он мог представлять собой промежуточное звено при переходе от mấs- к candrá-.

76. sleep / спать: RV sas- $\{$ sas- $\}$ - AV swap-\{svap-\}

В Ригведе в значении 'спать' употребляются корни sas- и svap-. Детали их распределения вызвали определенную научную полемику, о которой будет сказано ниже.

В Атхарваведе корень sas- уже употребляется всего один раз (именительный падеж действительного причастия настоящего времени sasán); соответственно, для ведийского списка, ориентированного на Атхарваведу, остается реконструировать только svap-.

Распределение sas- и svap- в тексте Ригведы в общих чертах может быть описано следующим образом: именно sas- употребляется в презенсе, данный глагол вообще представляет собой praesens tantum. От svap- засвидетельствована только одна форма императива 2 лица svapa 'спи' (RV VII, 55, 2) и дважды действительное причастие svapánt$(\mathrm{RV} \mathrm{V}, 44,13 ; \mathrm{RV}$ X, 164, 3). При этом от svap- образованы формы перфекта и каузатива (в том числе аористные) (Grassman 1873: 1625-1626). Анализ С. Джемисон, который представляется убедительным, позволяет говорить скорее о супплетивизме этих двух корней в ведийском, нежели о семантическом различии, вопреки мнению, высказанному в (Mayrhofer 1965). Как показывает исследовательница, непереходные презенсы от корня svap- необходимо признать в целом вторичными; реальные унаследованные из праязыка презентные формы представлены только вед. sásti 'спит' и т. д. (напрямую соответствует хеттскому šešzi 'спит; проводит ночь; отдыхает, покоится’). Ч. Р. Бартон присоединяется к данному мнению и устанавливает, что для и.-е. *ses- необходимо реконструировать непредельное (atelic) значение 'спать' и праязыковой презенс *sésti в противоположность предельному (telic) значению *swep- 'уснуть, заснуть' с праязыковым корневым аористом *swép-t (Barton 1985). Можно говорить о противопоставлении презентного корня *sesи аористного *swep-.

Примечательное распределение корней sas- и svap- в Ригведе в определенной степени соответствует хеттской ситуации. В хеттском также засвидетельствованы корни šе̌́- / šaš-, ср. šešzi ‘спит; проводит ночь; отдыхает, покоится’ (CHD Š: 439-445) и šupp- / šuppa- / šuppiya- (act. šuppiyezi / med. šuppari, šuptari 'засыпает’) (CHD Š: 607-608). Второй глагол вообще более редок, а значение 'засыпать' постепенно переходит к имперфективной основе šeške- (от šěs-), перед которой в предложении стоит клитика -za (CHD Š: 445).

Такую трактовку поддерживает П. Кочаров, рассматривая праиндоевропейские глаголы, имеющие значение 'спать', и их смысловые и грамматические различия (Kocharov 2016: 81-86).

Если данное предположение верно, для Ригведы основным глаголом 'спать' безусловно служит sas-, что соответствует лексической спецификации для данного глагола в (Kassian et al. 2010: 76):

1. People usually sleep in the night and keep awake by day.

2. Do not wake him up, he is sleeping.

1. Объчно ночью люди спят, а днем бодрствуют.

2. Не буди его, он спит.
Static verb. Should be kept apart from inchoatives like 'to fall asleep'.

Длительное состояние. Отличать от инхоативов вроде 'заснуть'. 
При этом svap- в Ригведе будет служить именно инхоативом.

На данном примере можно видеть, как от Ригведы к Атхарваведе произошло следующее развитие в лексиконе: корень sas- 'спать' исчез и был вытеснен близким по семантике корнем svap- 'уснуть'.

84. tail / хвост: AV p'uč

Основа púcha- не встречается в Ригведе, но в Атхарваведе однозначно обозначает 'хвост' (змеи AVŚ VII, 56, 6, быка AVŚ IX, 4, 13 и коровы AVŚ X, 9, 22).

В Ригведе по одному разу в прямом значении 'хвост' засвидетельствованы основы śépa- и śiśná-: cp. соответственно RV X, 105, 2 «двоих скакунов - хвосты (их) как у птицы» и RV I,105,8 «как крысы вгрызаются в (свои) хвосты». Второе значение обеих основ - 'penis', и именно в этом значении данные слова встречаются в Атхарваведе.

В индоарийских языках более позднего периода в значении 'хвост' преобладают рефлексы púcha- (Turner 1962-1985: 8249). Менее многочисленные продолжения имеет производная суффиксальная основа *śép-ya- (Turner 1962-1985: 12606-12607).

Слово púcha- не имеет ясной этимологии: М. Майрхофер полагает оптимальным вариантом сравнение с др.-в.-нем. fuhs 'лиса' и т. д., ср. торвали рӣ̌s 'лиса' < *pucchin 'хвостатый, имеющий хвост’ (EWAia II: 140). Я следую мнению, высказанному в Lubotsky 2001: 312, и рассматриваю púcha- как заимствование из неизвестного источника; в этом случае логично предполагать, что оно постепенно вытеснило индоарийские по происхождению основы.

94. water / вода: RV wa:r-\{vấr-\} / ud-'an- \{udán-\} - AV ud-a-k'a- \{udaká-\}

Это особенный случай. Для Ригведы необходимо постулировать супплетивную парадигму vấr- / udán- (род. п. udnás и т. д.) (Lubotsky 1997: 352, 1257; Lubotsky 2013), а в Атхарваведе и в более поздних текстах уже нормально употребляется udaká- (Kim 2020: 173; Bloomfield 1906: 257).

Существует мнение, что основа vấr- восходит к *wed-r при признании так называемого «эффекта Кортландта», перехода * $d>{ }^{*} h_{1}$ в консонантных кластерах, и родственна, таким образом, основе косвенных падежей udán- (Lubotsky 2013; Garnier 2014: 148-149; de Vaan 2008: 644).

В своей работе Trofimov 2017 я показываю, что с учетом семантики и распределения когнатов вед. vấr- в других индоевропейских языках необходимо возводить данную основу к отдельной праформе *weh ${ }_{1}$ - 'мокрота, сырость' и отделять ее от udán- и udaká- < *wed'вода', что дает для Ригведы дополнительный слот с основой другого происхождения.

2) Морфологические отличия Ригведы по сравнению с Атхарваведой.

В ряде случаев в Ригведе слово, оказывающееся главным кандидатом для списка, имеет тот же корень, что и в Атхарваведе, но при этом представлено другой основой (например, корневой против суффиксальной или с другим суффиксом).

65. rain / дождь: RV wrş-t'i- \{vrștí-\} - AV wars-'a- \{varșá-\}

В Атхарваведе именно слово varșá- является основным (Kim 2020: 624), в то время как синонимичная этимологически родственная основа с другим суффиксом, vrștí-, менее употребительна и встречается менее 10 раз как в Пайппаладе, так и в Шаунаке (Kim 2020: 659-660). В Ригведе, напротив, varșá- встречается только дважды (RV V, 58, 7; RV V, 83, 10), при этом более частотное vrștí- употреблено более 50 раз, а также засвидетельствовано в составе многих композитов (Lubotsky 1997: 1361-1362; BR-6 1871: 1346; Grassmann 1873: 1351-1352). Можно привести следующие примеры: RV I, 38, 8 «когда пролился их дождь»; 
RV II, 6, 5 «(дай) нам дождь с неба!»; RV II, 27, 15 «для него оба обращенных друг к другу (мира) набухают от дождя с неба» и т. д.

В данном случае $t$-основа заменяется тематической.

77. small / маленький: RV 'arb ${ }^{h}-a$ - $\{a ́ r b h a-\}-A V$ 'arb ${ }^{h}-a-k a-\{a ́ r b h a k a-\}$

В Ригведе основа без суффикса употребляется 12 раз против 6 с суффиксом (Lubotsky 1997: 139), а в Атхарваведе она засвидетельствована уже реже, чем árbhaka- (Kim 2020: 81; Whitney 1881: 36).

В Атхарваведе наряду с основами árbha- и árbhaka- употребляется основа álpa-, трижды в редакции Пайппалада и дважды в редакции Шаунака (Kim 2020: 83), cp. AVŚ IV, 16, 3: «И два океана - две стороны живота Варуны, и в этой малой капле воды он сокрыт»; AVŚ XI, 3, 23-24: «Тот, кто будет знать величие рисовой каши, Не сможет сказать ни «(Оно) малое», ни «(Оно) без добавлений», ни «Оно какое ни на есть». Также в составе композитов álpa-paśu- 'тот, у кого мало скота', álpa-śayu- 'название мелкого насекомого'; кроме того, есть лексема alpikā- (в гимнах Кунтапы AV 20.136.3) - по-видимому, слово, которое можно отнести к «вульгарно-сексуальному регистру» и должно передаваться русскими эквивалентами вроде малышка, крошка, детка (Kulikov 2011: 318-319; Kulikov 2012: 492).

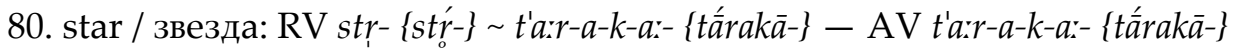

В Ригведе 8 раз засвидетельствован вариант с начальным s- (а именно инструменталис stŕ́bhis) (Lubotsky 1997: 1587; Grassman 1873: 1589), уже не встречающийся в более поздние эпохи развития древнеиндийского языка.

В Атхарваведе, как и позднее, употребляется только основа tấrakā- (по 5 раз в тексте как Пайппалады, так и Шаунаки) (Kim 2020: 303; Whitney 1881: 128).

Первая, засвидетельствованная в Ригведе, основа сохраняет начальный s-, содержавшийся в праформе * $h_{2}$ ster- 'звезда' (EWAia II: 755-756), соответственно, представляет собой более архаичный вариант.

3) Сложные случаи.

4. belly / живот: ud'ar-a- $\{$ udára- $\}$

Пучшим кандидатом на заполнение слота 4. belly / живот представляется основа udára- (BR-1 1855: 915; Grassmann 1873: 253; RIVELEX 2: 320). У данного слова наблюдается полисемия 'живот / утроба' (в том числе в переносном смысле). Ряд контекстов из Атхарваведы показывают, что оно имеет интересующее нас значение 'живот': AVŚ IV, 16, 7 «пусть сидит негодяй с обвислым животом»; AVŚ IV, 34, 1 «Брахман - ее голова, брихат ее спина, (напев) Вамадевы - живот рисовой каши» и т. д.

Стоит отметить, что слово встречается только в I, VIII и X мандалах Ригведы в следующих контекстах: RV I, 25, 15 «(как и) в утробах наших»; RV I, 30, 3 «когда эти (соки) с(ливаются) для мощного опьянения у него в животе»; I, 42, 9 «наполни живот!» (о Пушане); RV I, 162, 10 «(та) оставшаяся в животе пища, которая пахнет» (о коне); RV VIII, 1, 23 «Этот выжатый напиток, о благой, - пей, переполнив живот!» (об Индре) и т. д.

Близким синонимом традиционно считается kukșí-, переводимое как 'живот, брюхо' (Kim 2020: 224; BR-2 1858: 306-307; Grassmann 1873: 328). Однако тот факт, что лексема kukșí- в основном употребляется в двойственном числе, а в контексте AVŚ II, 33, 4 («Из внутренностей, из твоих кишок, из прямой кишки, из чрева (udára-), якшму из двух сторон живота (kukșí-), из потрохов(?), из пупа я вырываю у тебя!») kukșí- и udára- употреблены друг за другом, говорит в пользу того, что они обозначали разные части тела, особенно если учитывать анатомическую точность текстов Атхарваведы. Опираясь в том числе и на это обстоятельство, С. Джэмисон показывает, что первоначальное значение 
kukșí- - не 'живот’, а 'щека' (Jamison 1987). Она реконструирует семантический переход '(две) щеки' > 'ягодицы' ‘живот беременной' > 'живот' (Jamison 1987: 80). Приведенные соображения позволяют считать именно udára- основным рефлексом.

Таким образом, рассматриваемая синонимия развилась ввиду близости первоначальных значений, но это две разные основы с различной исходной семантикой.

Следует также отделять основу jațhára- с полисемией 'живот / желудок / утроба / внутренности' (Kim 2020: 276; BR-3 1861: 12-13; Grassmann 1873: 464-465). В своем первом значении эта основа в первую очередь обозначает специфически живот, наполненный сомой, особенно Индры и других божеств (ср. RV V, 34, 2; RV VI, 67, 7 и т. д.), соответственно, ее нельзя считать стилистически нейтральным синонимом.

Наконец, есть более редкий синоним vakṣánฺ̄-, который часто употребляется в значении 'нутро, недра, (материнская) утроба' (Kim 2020: 608; BR-6 1871: 616; Grassmann 1873: 1190), cp. RV I, 32, 1 «недра гор»; RV V, 42, 13 «в чреве дочери» и т. п. Вообще его значение и этимология неясны (EWAia II: 487).

22. earth / земля: $b^{h \prime} u:-m i-\{b h \underline{u} m i-\}$

Здесь три кандидата: основы kṣám-, prothiví- и bhúmi-. Наиболее солидной этимологи-

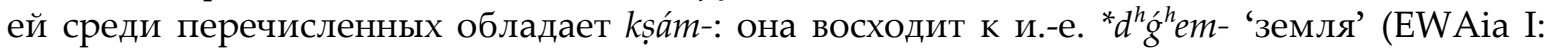
424-425). Тем не менее, основа kșám- уже в Ригведе употребляется только в определенных контекстах в противоположность dív- 'небо' (cp. RV I, 103, 1 «на земле здесь одно, на небе другое от нее») и адвербиально (cp. RV III, 8, 7 «(те,) что срубленные, (лежат) на земле $(k s ̦ a ́ m i) »)$. В Атхарваведе же эта основа - уже очевидный архаизм, употребляющийся 6 раз в Пайппаладе и 9 раз в Шаунаке в подобных контекстах, причем многие оказыва-

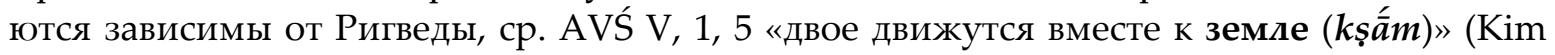
2020: 233; Whitney 1881: 92).

Намного более употребительна, особенно в Атхарваведе, основа prthiví- 'земля' (Kim 2020: 447-449; Whitney 1881: 188-189), которая при этом также обозначает прежде всего 'землю в противоположность небу' и землю как обожествленную сущность, божество (Grassmann 1873: 855-857).

В любом случае, и kșám-, и prothiví- никогда не имеют значения 'земля как почва', предполагаемого используемой семантической классификацией (Kassian et al. 2010: 57), а значат только 'земля как поверхность, ground'.

Соответственно, для базового термина 'земля' в ведийском подходит только слово bhúmi- с параллельной формой bhúmī- и полисемией 'земля (ground) / земля (почва) / страна' (Kim 2020: 506-507; BR-5 1868: 348-349; Grassmann 1873: 951). Слово bhúmi- также часто используется по отношению к обожествленной и персонифицированной Земле, как и упомянутые синонимы. Примеры: AVŚ III, 17, 5 «на счастье пусть взрезают землю хорошие лемехи!», AVŚ V , 11, 6 «пусть уползут дасы вниз в землю!» и т. д.

38. head / голова: fir-as- \{śíras-\} firr-s-'an- \{śīrșán-\} (косв.)

Несмотря на то, что значение 'голова' для основы śíras- устанавливается однозначно как в Атхарваведе, так и в Ригведе, проблема состоит в наличии достаточно близкого синонима mūrdhán- (Kim 2020: 539-540; Lubotsky 1997: 1080; BR-5 1868: 856-858; Grassmann 1873: 1053; MW 1899: 826).

Сама основа śíras- обыкновенно служит для обозначения 'головы' людей и антропоморфных существ, богов и животных: AVŚ IV, 14, 7 «голову козла положи в восточной стороне»; AVŚ IX, 8, 21 «из ног, из колен, из ягодиц, из промежности, острые боли спинного хребта, из головы - я заставил исчезнуть болезнь».

Основа mūrdhán- же неоднократно засвидетельствована в значении 'глава' или 'вершина', сp. RV I, 24, 5 «к вершине богатства». В связи с этим в Большом Петербургском 
словаре санскрита специально отмечается, что в древности это слово редко имеет прямое значение и в основном употребляется в переносных (BR-5 1868: 856). Также стоит отметить, что контекстов с основой mūrdhán- в Атхарваведе меньше (Kim 2020: 539-540; Whitney 1881: 228), чем в Ригведе (Lubotsky 1997: 1080; Grassman 1873: 1058), а śíras- и śírșánпо-прежнему частотны (Kim 2020: 686; Whitney 1881: 291-292).

Поскольку в семантической спецификации для аннотированных списков Сводеша, которой я пользуюсь, предлагается отличать слово 'голова' от «а) более узких терминов 'затылок', 'макушка' и т. п.», «в) метафорического переноса 'голова' > 'верхушка', 'начальник’ и т. п.» (Kassian et al. 2010: 63), mūrdhán- следует считать второстепенным синонимом.

45. know / знать: wid- $\{$ vid-\}

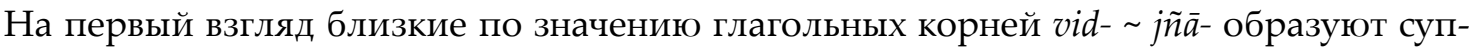
плетивную пару, поскольку первый образует прежде всего древний перфект véda со значением 'знать' и реже - корневой презенс vetti (Kümmel 2000: 501-504), а от второго в основном образуются презентные формы (Kim 2020: 290-291).

Однако искомый, согласно спецификации, «глагол, обозначающий уже имеющее место знание относительно какой-л. ситуации» (Kassian et al. 2010: 66) - это именно vid-, например, RV X, 11, 1 víśvam sá veda 'он знает все', ср. нем. 'der weiß alles' (Geldner).

При этом корень jи̃ $\bar{a}-$ как в Ригведе, так и в Атхарваведе имеет более специфическое значение 'узнавать, понимать' и 'иметь знакомство, знать (дорогу, человека), быть знакомым', которое как раз необходимо отличать от базового глагола 'знать', как он описан в Kassian et al. 2010: 66.

Это доказывается многочисленными контекстами с јӣ̄-, например, AVŚ XV, 12, 9: «он не знает ни пути, исхоженного отцами, ни (пути), исхоженного богами»; RV 10, 34, 4: «Отец, мать, братья говорят о нем: мы не знаем (его!) Уведите его связанным!»; RV 10, 114, 2: «Три Гибели сидят при этом, чтоб указывать, - ведь возницы (жертвы), которых далеко слышно, знают их хорошо» и т. д.

Соответственно, я склоняюсь к тому, что именно корень vid- должен быть вынесен как элемент 110-словного списка в значении 'знать'. Тем не менее, необходимо дальнейшее исследование по разграничению значений этих двух глаголов, тем более что иногда контексты с глаголом vid- переводятся при помощи нем. kennen, cp. RV II, 14, 10 véda ahám asya níb ${ }^{\mathrm{h}} \mathrm{r} t a m$ me etát «Ich kenne ihn; das steht für mich fest» (Geldner).

51. man / мужчина: nar- \{nár-\} и p'umã̃s- \{púmāms-\} pũs- \{púms-\}.

В Ригведе и Атхарваведе встречается несколько синонимов, служащих для обозначения 'мужчины': это основы nár-, vīrá- и púmāṃs- (в косвенных падежах púms-). Дополнительные синонимы vósșan- 'мужественный / сильный / мужчина / самец / самец любого животного и т. д.’ (BR-6 1871: 1338-1340; Grassmann 1873: 1345-1348; MW 1899: 1012) и márya- / máriya- 'молодой человек в расцвете сил' очевидно имеют более специфическое значение и не годятся в качестве кандидатов.

Интересно, что nár- и vīrá- имеют надежную индоиранскую или индоевропейскую этимологию с соответствиями, которые указывают в родственных языках в том числе и

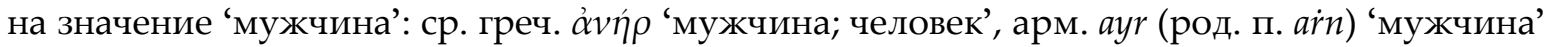
и т. д. (EWAia II: 19-20), второе - лат. uir 'муж, мужчина / супруг', гот. wair 'муж / мужчина / человек’ и т. д. (EWAia II: 569-570).

Для ведийского списка, тем не менее, я выбираю только два из этих синонимов, nárи púmāṃs- púms- на основании анализа употребления рассматриваемых основ в тексте.

Первый, часто употребляющийся и в Атхарваведе, и в Ригведе, имеет точный антоним 'женщина', nấri- nấrī-, и иногда употребляется в этой оппозиции: RV I, 43, 36; RV VIII, 77, 8. Примером употребления в своем основном значении может служить кон- 
текст AVŚ XIV, 2, 9 «сейчас, о мужи, услышьте же от меня, каким благословением супружеская чета достигнет (всего) ценного».

Подобным образом и слово púmāṃs- púmss- имеет антоним strí- 'женщина / самка' и также употребляется в контекстах противопоставления мужчины женщине: AVŚ I, 8, 1 «кто это совершил, женщина (или) мужчина, пусть этот человек здесь объявит себя!»; AVŚ V , 14, 6 «если женщина или если мужчина во зло сотворили колдовство».

К сожалению, однозначных примеров, где для мужчин и женщин описывались бы именно присущие им занятия (вроде охоты / плетения корзин), в ведийских текстах обнаружить не удается.

В то же время vīrá- чаще всего имеет значение 'герой' и постоянно употребляется по отношению к божествам, cp. RV VI, 21, 6 «мы воспеваем тебя (Индра), о герой, привлекаемый молитвой»; AVŚ III, 23, 2 «да родится тут герой, сын у тебя, десятимесячный!».

60. night / ночь: r'a:-tr-i:- \{ráatrī- $\} \sim$ r'a:-tr-i-\{rátri-\}

В ведийском есть три основы, которые могли бы теоретически претендовать на заполнение данного слота.

Более древние по происхождению основы kṣáp- (BR-2 1858: 530; Grassmann 1873: 362) и nákt- (BR-4 1865: 6; Grassmann 1873: 703) уже в Ригведе употребляются как наречия или в связанных контекстах в устоявшихся поэтических выражениях (Lubotsky 1997: 458-459, 785). Для kṣáp- стандартны употребления адвербиального типа, cp. RV IX, 99, 2 «и вот, приготовленный ночью, он (Сома) ныряет вперед к наградам») и контексты с основой ușás- 'заря' во множественном числе (cp. RV VI, 52, 15 «Чтобы (мы) процветали (и) ночами, (и) и на утренних зорях!»; RV VII, 15 «свети (Агни) в ночах и на утренних зорях!»). В Атхарваведе эта основа уже не употребляется (Kim 2020: 235; Whitney 1881: 92), позднее

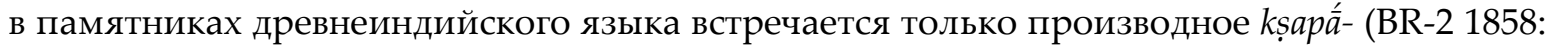
531). Соответственно, это слово никак не может претендовать на заполнение слота.

Похожим образом употребляется nákt-: это либо обожествленная сущность, либо слово, употребляемое вместе с иșás- ‘заря', либо наречие náktam 'ночью', произведенное от винительного падежа единственного числа соответствующей основы, часто вместе с противоположным по значению dívā 'днем’, cp. AVŚ V, 7, 3 «пусть будет в порядке днем и ночью наше награждение, созданное богами!», RV I, 24, 12 «О том ночью, о том днем мне твердят».

Поэтому базовым обозначением 'ночи' в ведийском языке можно считать основу rátrī(Kim 2020: 594-595). Cp. AVŚ II, 8, 2 «Прочь пусть засветит эта ночь (кшетрию)». Она также может выступать как обожествленная персонифицированная сущность, сp. RV I, 35, 1 и гимн к Ночи AVŚ XIX, 49, подробно с параллелями в ведийской литературе см. Kulikov 2010.

64. person / человек: క̌an-a- \{jána-\}

Для слота 'человек' есть целых три кандидата, mánuṣa- (RV, в AV только субстантивированное прилагательное тапușyá- manușíya-), púruṣa- púrușa- и jána-. Их употребление в тексте Ригведы и Атхарваведы показывает примечательное распределение: mánușaи manușyá- manușíya- обозначают человека в противоположность божествам, púrușapúrușa- человека в оппозиции к (другим) животным, jána- человека вообще (Trofimov 2019). Для последнего в связи с этим частотно употребление во множественном числе в значении 'люди' (например, RV II, 12, 1 «тот, о люди, Индра!» и далее неоднократно в тексте того же гимна).

В связи с этим необходимо выбрать ја́na- как самый нейтральный синоним.

Примечательно, что в различных индоарийских языках все четыре основы имеют рефлексы с базовым значением 'человек' (Turner 1962-1985: 5098; 8289; 9827-9828), причем преобладают потомки производного manușyá- manușíya-, на втором месте - продолжения jána-, в достаточно небольшом количестве языков - продолжения púrușa- и mánușa-. 
89. tooth / зуб: dant- \{dánt-\}

В данном случае в Ригведе и Атхарваведе встречаются два слова, dánt- и jámbha-, оба имеют хорошую индоевропейскую этимологию и связаны с когнатами в других языках со значением 'зуб': ср, например, лат. dens, dentis 'зуб' (EWAia I: 695-696) и тох. А kam, тох. В kете 'зуб', праслав. ‘zobr 'зуб' (EWAia I: 572-573). Очевидно, что определение основного понятия в ведийском является дополнительным аргументом в пользу реконструкции *dent- или *'ó $о b^{h}{ }^{\prime}$ - на прауровень в качестве основного обозначения 'зуба'.

Несмотря на то, что синоним јámbha- чаще употребляется (особенно в Ригведе), он имеет специфическую семантику. В основном это слово применяется в Ведах в метафорическом смысле, когда речь идет о 'зубах огня', то есть бога Агни (ср. RV I, 143, 5 «(этот) Агни ест-пожирает острыми зубами»). Также имеет значение 'челюсть', 'ряд зубов', часто отраженное в словарях и переводах, ср. RV VIII, 60, 14 «Не устоять перед твоими чепюстями, о Агни-бык» и т. д.

Кроме того, необходимо отметить, что јámbha- является производным по отношению к глаголу jabh- jambh- 'хватать; защелкивать(ся)', а это хорошо согласуется со значением 'ряд зубов / челюсти'.

История и внутренние связи рассматриваемого ведийского слова прослежены в работах (Narten 1965; Mumm 1999). Оба исследователя приходят к выводу, что слово jámbhaимело в ведийском значение 'ряд зубов', 'челюсть'. В связи с этим очевидно, что основное обозначение 'зуба' в Ведах - именно dánt-. Это хорошо согласуется с такими парами

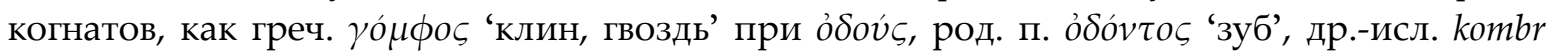
'гребень' при tonn 'зуб' и т. д.

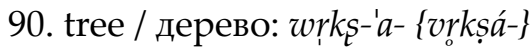

Значение ‘дерево’ подтверждается для основы vroșá- достаточным количеством контекстов: AVŚ X, 7, 38 «как ветви, разошедшиеся вокруг ствола дерева»; RV III, 45, 4 «стряхни, как спелый плод крюком с дерева»; RV IV, 20, 5 "спелое дерево (с плодами)"; RV VI, 24, 3 «ветви дерева».

Близкий синоним, основа vána-, имеет значение 'дерево, лесное дерево' большей частью в Ригведе (Lubotsky 1997: 1228-1229; BR-6 1871: 666-667; Grassmann 1873: 1206-1207; MW 1899: 917-918), в Атхарваведе это уже в основном 'лес', как и в более поздних памятниках, ср. AVŚ VI, 33, 1 «чтобы подталкивать людей, лес, небо»; AVŚ VIII, 6, 11 «кто поднимает шум в лесу».

Часто употребляемая основа vanaspáti- '(лесное) дерево' буквально переводится как 'повелитель леса' (BR-6 1871: 673-674; Grassmann 1873: 1208-1209) и употребляется в стилистически окрашенных контекстах, например, AVŚ IV, 3, 1 «божественное дерево», AVŚ V , 27, 11 «о дерево, отпусти (жертвенное животное), даря (его)!»

Также не подходит в качестве кандидата на основное обозначение dáru- 'деревянное бревно, балка / дрова' (Kim 2020: 339; BR-3 1861: 595; Grassmann 1873: 595-596), восходящее к и.-е. *dor-u- / *der-u- / *dr-еw- 'дерево'.

99. woman / женщина: n'a:r-i- \{nấri-\} n'a:r-i:- \{nấrī $\}$ и str-i:- $\{$ strí̀- $\}$

Как и в случае со слотом 'мужчина', засвидетельствован большой ряд синонимов, имеющих определенные коннотации или указывающих на возрастную семантику. Среди них gná- ‘божественная женщина, женское божество' (BR-2 1858: 830; Grassmann 1873: 415; MW 1899: 370); jáni- 'жена' (BR-3 1861: 29; Grassmann 1873: 475), yóṣạā- ‘девочка, девушка’ с вариантами основы yóșā- и yoșít- (BR-6 1871: 200; Grassmann 1873: 1128), ménā'самка любого животного / женщина' (BR-5 1868: 903-904; Grassmann 1873: 1064). 
В качестве элементов списка Сводеша необходимо выбрать nấri- nấrī- (Kim 2020: 395; BR-4 1865: 117; Grassmann 1873: 725) и strí- (Kim 2020: 777; BR-7 1875: 1275-1276; Grassmann 1873: 1596), прямые антонимы к nár- и púmāṃs- púṃs- 'мужчина' соответственно.

Проведенное исследование показывает, что ведийский список может быть в целом успешно составлен при должном привлечении данных текстов и с опорой на определенный семантический стандарт. Общее число случаев расхождения между Атхарваведой и Ригведой - всего 6 основ. Морфологические различия между текстами Ригведы и Атхарваведы засвидетельствованы в 3 случаях. В 10 случаях было несколько весомых кандидатов на заполнение слота, но работа с текстом позволила сделать уверенный выбор базовых терминов. В тексте Атхарваведы 4 лакуны: 3. bark / кора; 50. louse / вошь; 69. round / круглый; 105. short / короткий. По две основы в главный слот вынесено 5 раз из-за супплетивизма (6 раз для Ригведы, где дополнительно наблюдается супплетивизм vấr- / udán- 'вода') и 5 раз из-за неснимаемой синонимии.

\section{References}

Abaev, V. I. 1958-1995. Istoriko-ètimologičeskij slovar' osetinskogo jazyka. V 4-x tomax [Historical-Etymological Dictionary of Ossetic. In 4 volumes]. Moskva-Leningrad: Izdatel'stvo AN SSSR.

Bammesberger, Alfred. 1982/83. Zur Entstehung der vedischen Imperative auf -(s)i. Zeitschrift für vergleichende Sprachforschung 96: 1-5.

Barton, Charles. 1985. PIE *suep- and *ses-. Die Sprache 31: 17-39.

Bloomfield, Maurice. 1906. A Vedic concordance, being an alphabetic index to every line of every stanza of the published Vedic literature and to the liturgical formulas thereof, that is an index to the Vedix Mantras, together with an account of their variations in the different Vedic books. Cambridge, MA: Harvard University Press.

Bloomfield, Maurice. 2008. Maurice Bloomfield's A Vedic Concordance Enhanced with New Material Taken from Seven Vedic Texts. Edited by Marco Franceschini. Harvard Oriental series 66. Cambridge, MA: Harvard University Press.

BR = Böhtlingk, Otto, Rudolph Roth. 1855-1875. Sanskrit Worterbuch, herausgegeben von der kaiserlichen Akademie der Wissenschaften, bearbeitet von Otto Böhtlingk und Rudolph Roth. 7 Bde. St-Petersburg: Eggers.

Cardona, George. 1965. The Vedic imperatives in -si. Language 41: 1-18.

$\mathrm{CHD}=$ P. M. Goedegebuure, H. G. Güterbock, H. A. Hoffner, T. P. J. van den Hout (eds.) 1980-. The Hittite Dictionary of the Oriental Institute of the University of Chicago. Chicago: The Oriental Institute of the University of Chicago.

Elizarenkova, T. J. (translator). 2005-2010. Atharvaveda. V 3-x tomax [Atharvaveda. In 3 volumes]. Moskva: Vostočnaja literatura RAN.

Elizarenkova, T. J. (translator). 1989-1999. Rigveda. V 3-x tomax [Rigveda. In 3 volumes]. Moskva: Nauka.

ESIJ = V. S. Rastorgueva, D. I. Edel'man. 2000-. Ėtimologičeskij slovar' iranskix jazykov [Etymological dictionary of the Iranian languages]. Moskva: Vostočnaya literatura RAN.

EWAia I-II = Manfred Mayrhofer. Etymologisches Wörterbuch des Altindoarischen. I-II Bde. Heidelberg: Universitätsverlag Winter.

Garnier, Romain. 2014. Nouvelles considérations sur l'effet Kortlandt. Glotta 90: 139-159.

Geldner, Karl F. 1951. Der Rig-Veda aus dem Sanskrit ins Deutsche übersetzt. 3 Bde. London and Wiesbaden: Verlag Otto Harrassowitz.

Gotō, Toshifumi. 1987. Die “I. Präsensklasse” im Vedischen. Wien: Verlag der Österreichischen Akademie der Wissenschaften.

Gotō, Toshifumi. 2013. Old Indo-Aryan Morphology and its Indo-Iranian Background (Veroffentlichungen zur Iranistik): In cooperation with Jared S. Klein und Velizar Sadovski. Wien: Austrian Academy of Sciences Press.

Grassmann, Hermann G. 1873. Wörterbuch zum Rig-Veda. Leipzig: F.A. Brockhaus.

Jamison, Stephanie W. 1982. "Sleep" in Vedic and Indo-European. Zeitschrift für vergleichende Sprachforschung 96: 6-16.

Jamison, Stephanie W. 1987. Linguistic and philological remarks on some Vedic body parts. In: Calvert Watkins (ed.). Studies in Memory of Warren Cowgill (1929-1985). Papers from the Fourth East Coast Indo-European Conference. Cornell University, June 6-9, 1985: 66-91. Berlin / New York: Walter de Gruyter. 
Jamison, Stephanie W., Joel P. Brereton. 2014. The Rigveda: the earliest religious poetry of India. Oxford University Press.

Hill, Eugen. 2007. Die Aorist-Präsentien des Indoiranischen. Untersuchungen zur Morphologie und Semantic einer Präsensklasse. Bremen: Hempen Verlag.

Kassian, Alexey, George Starostin, Anna Dybo, Vasily Chernov. 2010. The Swadesh wordlist. An attempt at semantic specification. Journal of Language Relationship 4: 46-89.

Kassian, Alexey. 2011. Annotated 50-item wordlist of the basic lexicon of the Ancient Greek languages (the idiolect of Herodotus). Journal of Language Relationship 6: 65-100.

Kim, Jeong Soo. 2020. Index Verborum der Paippalādasaṃhitā und der Śaunakasaṃhitā des Atharvaveda (eine vorläufige Version). Ms. (in print).

Kocharov, Peter. 2016. Proto-Indo-European lexical aspect and stem patterns. Faits de langues 47: 75-88.

Kulikov, Leonid. 1997. Vedic mriyáte and other pseudo-passives: notes on an accent shift. In: Irén Hegedus, Peter A. Michalove, Alexis Manaster Ramer (eds.). Indo-European, Nostratic, and Beyond: Festschrift for Vitalij V. Shevoroshkin (JIES monograph series; 22): 198-205. Washington DC: Institute for the Study of Man.

Kulikov, Leonid. 2008. The Vedic type patayati revisited: Semantic oppositions, paradigmatic relationships and historical connections. In: Alexander Lubotsky, Jos Schaeken, Jeroen Wiedenhof (eds.). Evidence and Counterevidence: Essays in honour of Frederik Kortlandt. Vol. I. Balto-Slavic and Indo-European Linguistics. (Studies in Slavic and General Linguistics 32): 245-261. Amsterdam: Rodopi.

Kulikov, Leonid. 2010. Atharvaveda-Śaunakīya 19.49.1 = Atharvaveda-Paippalāda 14.8.1: an etymological note on Vedic rátrī- 'night'. In: T. M. Nikolaeva, P. M. Arkad'ev, A. A. Zaliznjak, N. N. Kazanskij (eds.)ю Issledovanija po lingvistike i semiotike: Sbornik statej k jubileju Vjač. Vs. Ivanova: 174-179. Moskva: Jazyki slavjanskix kul'tur.

Kulikov, Leonid. 2011. Passiv, antikauzativ, "intranzitiv”? K interpretacii trex vedijskix prezensov s suffiksom -ya(jāyate, mriyáte, yabhyate) [Passive, anticausative, "intransitive”? Notes on interpretation of three Vedic present formations with the suffix -ya- (jāyate, mriyáte, yabhyate)]. Indoevropejskoe jazykoznanie i klassicheskaja filologija. Materialy chtenij 14: 310-322.

Kulikov, Leonid. 2012. The Vedic -ya-presents: Passives and intransitivity in Old Indo-Aryan. Amsterdam: Rodopi.

Kulikov, Leonid. 2017. Ch. 6. Indo-Aryan. In: Mate Kapović (ed.). The Indo-European Languages: 214-262. London: Routledge.

Kümmel, Martin Joachim. 1996. Stativ und Passivaorist im Indoiranischen. (Historische Sprachforschung, Ergänzungsheft 39). Göttingen: Vandenhoeck \& Ruprecht.

Kümmel, Martin Joachim. 2000. Das Perfekt im Indoiranischen. Eine Untersuchung der Form and Funktion einer ererbten Kategorie des Verbums und ihrer Weiterentwicklung in den altindoiranischen Sprachen. Wiesbaden: Reichert Verlag.

LIPP = Dunkel, George E. 2014. Lexikon der indogermanischen Partikeln und Pronominalstämme. Band 1: Einleitung, Terminologie, Lautgesetze, Adverbialendungen, Nominalsuffixe, Anhänge und Indices. Band 2: Lexikon. Heidelberg: Winter.

LIV $^{2}=$ Rix, Helmut (ed.). 2001. Lexikon der indogermanischen Verben. Die Wurzeln und ihre Primärstammbildungen. Wiesbaden: Dr. L. Reichert Verlag.

Lubotsky, Alexander. 1997. A R.gvedic Word Concordance. 2 vols. New Haven: American Oriental Society.

Lubotsky, Alexander. 2001. The Indo-Iranian substratum. In: Christian Carpelan, Asko Parpola, Petteri Koskikallio (eds.). Early contacts between Uralic and Indo-European: linguistic and archaeological considerations: 301-317. Helsinki: Suomalais-Ugrilainen Seura.

Lubotsky, Alexander. 2002. Atharvaveda-Paippalada, Kanda Five: Text, Translation, Commentary. Cambridge, MA: Harvard University Press.

Lubotsky, Alexander. 2013. The Vedic paradigm for 'water'. In: A. I. Cooper, J. Rau, M. Weiss (eds.). Multi Nominis Grammaticus. Studies in classical and Indo-European linguistics in honor of Alan J. Nussbaum on the occasion of his sixty-fifth birthday: 159-164. Ann Arbor / New York: Beech Stave Press.

MacKenzie, David N. 1986. A concise Pahlavi dictionary. London / New York / Toronto: Oxford University Press.

Mayrhofer, Manfred. 1965. Hethitisches und arisches Lexikon. Indogermanische Forschungen 70: 245-257.

MW 1899 = Monier-Williams, M. A. Sanskrit-English dictionary: etymologically and philologically arranged with special reference to cognate Indo-European languages. Oxford: Clarendon Press.

Mumm, Peter A. 1999. Deutsch Kamm, Kimme und die Bedeutung von idg. *gomb ${ }^{\mathrm{h}}$-o-, * ǵemb $^{\mathrm{h}}$-. In: Wolfgang Schindler, Jürgen Untermann (eds.). Grippe, Kamm und Eulenspiegel. Festschrift für Elmar Seebold zum 65. Geburtstag: 295-312. Berlin / New York: De Gruyter. 
Narten, Johanna. 1965 Ai. jámbha-, gr. үó $\mu \phi o s$ und Verwandtes. Zeitschrift für vergleichende Sprachforschung 79: 255-264.

Orlandi, Chatia. 1992. Gli inni dell' Atharvaveda: Śaunaka. Traslitterazione a cura di Chatia Orlandi e Saverio Sani. Pisa: Giardini.

RIVELEX 1-2 = Krisch, Th. (ed). 2006-. RIVELEX. Rigveda-Lexikon. Bd. 1. Words beginning with "a”. Bd. 2. Words beginning with other vowels than " $a$ ". Graz: Leykam.

Roth, Rudolf von, William D. Whitney. 1856-1857. Atharvaveda Atharva Veda Sanhita, herausgegeben von R. Roth und W.D. Whitney. Berlin: F. Dümmler.

Shields, Kenneth. 1997. The origin of the Vedic $2^{\text {nd }}$ sing. Imperative in «-si». Indo-Iranian Journal 40: 149-155.

Starostin, George. 2019. Chinese basic lexicon from a diachronic perspective: implications for lexicostatistics and glottochronology. Journal of Language Relationship 17: 153-176.

Starostin, Sergei (ed.). 1998-2005. The Tower of Babel. An etymological database project. Available at: http://starling.rinet.ru/ [accessed 12.11.2020].

Tedesco, Paul M. 1944. The Supposed Rigvedic Present márate. Language 20: 212-222.

Trofimov, A. A. 2017. Vedijskie osnovy vấr-, udán- i udaká- 'voda': ix paradigmatičeskie i ètimologičeskie otnošenija [Vedic stems vār-, udán-, udaká- 'water' and their paradigmatic and etymological interrelations]. Journal of Language Relationship 15: 181-192.

Trofimov, A. A. 2019. Sootnošenie slov jána-, púrușa- i mánuṣa- ‘čelovek’ v Rigvede i Atharvavede [The correlation between the words jána-, púrușa- and mánușa- 'person' in Rigveda i Atharvaveda]. In: Sovremennoe sostojanie indoevropejskogo jazykoznaniya i sanskritologii. Sbornik naučnoj konferencii, posvyǎ̌čennoj pamjati zaslužennogo professora Moskovskogo universiteta imeni M. V. Lomonosova Very Aleksandrovny Kočerginoj (1924-2018): 310-315. Moskva: MCNMO.

Turner, Ralph L. 1962-1985. A comparative dictionary of Indo-Aryan languages. London: Oxford University Press.

Vaan, Michiel de. 2008. Etymological dictionary of Latin and the other Italic languages. Leiden/Boston: Brill.

Vishva Bandhu, Bhim Dev, S. Bhaskaran Nair (eds.). 1935-1965. Vaidika-Padānukrama-Koșa: A Vedic WordConcordance. Hoshiarpur: Vishveshvaranand Vedic Research Institute.

Wackernagel, Jackob. 1896. Altindische Grammatik. Bd. I. Lautlehre. Göttingen: Vandenhoeck and Ruprecht.

Wackernagel, Jackob. 1930. Altindische Grammatik. Bd. III. Nominalflexion - Zahlwort - Pronomen. Göttingen: Vandenhoeck and Ruprecht.

Whitney, William D. 1881. Index verborum to the published text of the Atharva-Veda. Journal of the American Oriental Society 12: 1-383.

Whitney, William D. 1885. The roots, verb-forms, and primary derivatives of the Sanskrit language: a supplement to his Sanskrit grammar. Leipzig: Breitkopf and Hartel.

Witzel, Michael. 1997. The Development of the Vedic Canon and its Schools: The Social and Political Milieu. In: Michael Witzel (ed.). Inside the Texts, Beyond the Texts: New Approaches to the Study of the Vedas, Harvard Oriental Series, Opera Minora; vol. 2: 257-348. Cambridge: Harvard University Press.

Witzel, Michael, Gotō Toshifumi, Mislav Ježic, Eijiro Dōyama. 2007-. Rig-Veda - Das heilige Wissen. Erster und zweiter Liederkreis. Dritter bis fünfter Liederkreis. Frankfurt am Main und Leipzig, Berlin: Verlag der Weltreligionen.

Artem Trofimov. An attempt at an annotated Swadesh wordlist for Vedic Sanskrit

The goal of the present paper is to illustrate certain philological and semantic issues that arise during the compilation of the 110-item Swadesh wordlist for the Vedic language, which is itself a necessary procedure for any satisfactory lexicostatistical analysis of Indo-Iranian and Indo-European data. The language of the Atharva Veda, the second of the Vedas, was chosen as the main idiom, since it does not have quite as many lacunae and is more stylistically neutral than the other texts. For the purposes of the wordlist, I have applied the semantic specifications currently used in the GLBD (Global Lexicostatistical Database). The text of the Atharva Veda was subsequently compared with the Rig Veda in order to obtain more reliable and comprehensive results and to study linguistic evolution at the early stages of development of the Vedic language. Research shows that 87 items of the Vedic list are more or 
less uncontroversial. Six meanings correspond to different stems in the Atharva Veda and the Rig Veda; there are also three cases of consistent morphological differences between the two texts. In 10 cases, it was necessary to choose the most appropriate candidate from a variety of synonyms. Only four lacunae remain in the text of Atharva Veda. Finally, there are five cases of suppletive stems and five cases of synonymy. The study shows that the Swadesh list for Vedic can be successfully compiled based on textual data and with the application of a strict semantic standart.

Keywords: lexicostatistics; Swadesh list; Vedic language; Atharva Veda; Rig Veda; synonymy; suppletivism. 